\title{
Stress, coping and attitudinal change towards medical profession during COVID-19 pandemic among health care professionals in India: a cross sectional study
}

\author{
Savita Chahal ${ }^{1}$, Nikhil Govil ${ }^{2}$, Nishu Gupta ${ }^{3}$, Anuradha Nadda ${ }^{4}$, Prashant Srivastava ${ }^{5}$, Shilpi \\ Gupta $^{6}$, Priyanka Dang ${ }^{7}$ \\ ${ }^{1}$ Assistant Professor, Department of Psychiatry, Kalpana Chawla Government Medical College, \\ (KCGMC), Karnal, Haryana. \\ ${ }^{2}$ Assistant Professor, M.D., Department of General Medicine, Kalpana Chawla Government Medical \\ College (KCGMC), Karnal, Haryana. \\ ${ }^{3}$ Department of Pediatrics, PGIMER Satellite Centre, Sangrur, Punjab, India. \\ ${ }^{4}$ Assistant Professor, Department of Community Medicine, Gian Sagar Medical College, Banur, Patiala, \\ Punjab, India. \\ ${ }^{5}$ Psychiatric Social Worker, Department of Psychiatry, Kalpana Chawla Government Medical College \\ (KCGMC), Karnal, Haryana. \\ ${ }^{6}$ Assistant Professor, Department of Community Medicine, Maharishi Markandeshwar Institute of \\ Medical Sciences and Research, Mullana (Ambala), Haryana. \\ ${ }^{7}$ Clinical Psychologist, Department of Psychiatry, Kalpana Chawla Government Medical College \\ (KCGMC), Karnal, Haryana.
}

Corresponding author: Nikhil Govil

Email - govilnikhil37@gmail.com

\begin{abstract}
Background: The COVID-19 pandemic has caused adverse psychological and social effects on health care professionals (HCPs). We aimed to evaluate the magnitude of psychological distress, social impact and coping strategies among HCPs.

Methodology: It was a cross sectional study conducted on HCPs in India. Convenient sampling with snow ball sampling technique was used. The link of a semi structured online questionnaire having four domains viz. socio-demographic and professional characteristics, effect on family and social life, perceived psychological distress and coping methods and change in attitude towards medical profession was sent to the participants through various social media.

Results: There were a total of 626 respondents including 385 doctors, 124 nursing staff and 117 paramedical HCPs. Significantly higher number of HCPs working in COVID institutes worked away from their hometown $(p<0.001)$ and had to send their children to relatives or other family member's house $(p=0.004)$. A significantly greater number of HCPs from COVID institutes experienced psychological distress compared to their Non-COVID counterparts $(\mathrm{p}=0.001)$. Fear of spreading coronavirus infection to family members was the most important reason (52.4\%) of psychological distress. $13.4 \%$ of the HCPs wanted to quit their job instantly if given choice and $15.8 \%$ regretted being a health care professional. Watching TV or digital platforms was the most commonly (55.27\%) used coping strategy.

Conclusion: The study concludes that the COVID-19 pandemic resulted in increased psychological distress, adverse social impact and negative attitude towards medical profession among HCPs.
\end{abstract}

Key Words: COVID-19, mental health, psychological distress, social impact, family life, attitude, health care professionals

(Paper received $-21^{\text {st }}$ June 2020, Peer review completed $-30^{\text {th }}$ July 2020, Accepted $-30^{\text {th }}$ July 2020) 


\section{INTRODUCTION}

The first case of coronavirus disease originated in the Hubei province of China on December 8, 2019 [1]. Since then, Coronavirus disease 2019 (COVID-19) pandemic has been rapidly spreading worldwide and on 11th March 2020, World Health Organization (WHO) declared it the global pandemic [2]. According to World Health Organization tally, there have been 7.9 million confirmed COVID-19 cases and $434 \mathrm{~K}$ deaths globally as on 16 June 2020 (1.57 pm CEST) [3] while the corresponding figures for India stood at 3,43,091 and 9900 respectively [4]. This pandemic has jeopardized the health care system of countries across the world. Facing this critical situation, health care professionals (HCPs) are at a high risk of developing psychological distress and other mental health symptoms as some previous studies on COVID-19 suggest [5-8]. This pandemic is likely to have adverse social impact on the lives of all people and more so among health care professionals. A change in attitude towards medical profession is another expected outcome of this pandemic. Though there have been a few recent studies exploring the psychological impact of COVID -19 pandemic on health care professionals; social impact and attitudinal change towards medical profession, however, have not yet been researched well. Therefore, this study is an attempt to evaluate the magnitude of psychological distress, analysis of potential reasons associated with perceived psychological distress, social impact and change in attitude towards medical profession among healthcare professionals during COVID-19 and also to explore various coping methods that were used by them to deal effectively with the exceptional circumstances posed due to COVID-19 pandemic.

\section{METHODOLOGY}

\section{Study design}

It was a cross-sectional study conducted on the health care professionals in India. The study participants were assured of the confidentiality and a written informed consent was sought from them at the beginning of the study.

\section{Sample size and sampling}

Taking $\alpha=0.05, Z \alpha=1.96$, acceptable margin of error 0.05 (1) and $74 \%$ (perceived moderate to severe psychological stress) prevalence of psychological stress from Grover S (Grover et al., 2020); the sample size came out to be 540 by using the formula $\mathrm{N}=\mathrm{Z}_{\alpha}{ }^{2} \times \mathrm{P}(1-\mathrm{P}) / \mathrm{l}^{2}$. Taking $10 \%$ non-response rate final sample size came out to be 594. A convenience sampling was used for the purpose of this research with the minimum target sample of 594 .

\section{Methodology}

The survey was completed in a period of 20 days from $16^{\text {th }}$ April to $5^{\text {th }}$ May 2020. Doctors, paramedical heath care professionals (technicians, pharmacists, occupational therapy psychosocial professionals, and physiotherapists) and nursing staff, formed the study unit. HCPs of allopathic system, willing to participate in the study, aged $\geq 18$ years, able to understand English, and having internet access were included in the present study. Sanitation workers, administrative staff and HCPs with overt psychiatric illnesses were excluded from the study. A semi- structured, online questionnaire comprising of four sections was designed by the investigators using google forms with consent form appended to it. Section A) had questions related to socio-demographic and professional characteristics, Section B) focused upon effect on family and social life, Section C) assessed about perceived psychological distress, possible reasons for psychological distress and various coping methods adopted by participants to deal with difficulties posed by COVID-19 and Section $\mathrm{D}$ ) enquired regarding change in attitude towards medical profession.

The link of the questionnaire was sent through WhatsApp, e-mails and other social media to the acquaintances of the investigators along with the request to escalate the survey further to as many health care professionals as achievable within India. On receiving and clicking the link the participants got auto directed to the informed consent. Those who consented to participate by clicking on 'Yes' in the consent 
form were directed to fill up the set of several questions arranged in four different sections that appeared sequentially.

The study participants were divided into two groups based on whether they worked in a dedicated COVID health care facility or Non- COVID health institute.

\section{STATISTICAL ANALYSIS}

Data analysis was done by SPSS statistical software version 20.0 (IBM Corp., Armonk, NY, USA). The p value was fixed as $\leq 0.05$. Pearson's Chi-square test and independent $t$ test was used for analysis.

\section{RESULTS}

There was an almost equal representation of either gender from both COVID and Non- COVID health care facilities. One third (36\%) of the study subjects were in the age group of 30-40 years. More than half of the respondents were married and majority hailed from nuclear families. 235 (37\%) participants had dependent elders in the family and $43.7 \%$ had dependent children. Majority of the respondents from COVID health care facilities (83.1\%) worked in government institutes (Table 1).

Table 1: Socio-demographic characteristics of study participants in COVID and Non-COVID health care facilities $(n=626)$

\begin{tabular}{|c|c|c|c|}
\hline Characteristics & $\begin{array}{c}\text { Non-COVID HCPs } \\
\mathbf{n}=344\end{array}$ & $\begin{array}{c}\text { COVID HCPs } \\
\mathrm{n}=282\end{array}$ & $\begin{array}{c}\text { Total } \\
n=626\end{array}$ \\
\hline \multicolumn{3}{|c|}{ Gender } & \\
\hline Male & $139(49.3)$ & $161(46.8)$ & $300(47.9)$ \\
\hline Female & $143(50.7)$ & $183(53.2)$ & $326(52.1)$ \\
\hline \multicolumn{3}{|c|}{ Age Group (in years) } & \\
\hline $18-25$ & $75(26.6)$ & $72(20.9)$ & $147(25.3)$ \\
\hline $25-30$ & $65(23.0)$ & $97(28.2)$ & $162(25.9)$ \\
\hline $31-40$ & $103(36.5)$ & $125(36.3)$ & $228(36.4)$ \\
\hline$>40$ & $39(13.8)$ & $50(14.5)$ & $89(14.2)$ \\
\hline \multicolumn{3}{|c|}{ Mean age (SD) } & \\
\hline Male & $29.6(7.3)$ & $30.9(6.9)$ & $34.9(8.4)$ \\
\hline Female & $35.4(9.2)$ & $34.5(7.8)$ & $30.3(7.1)$ \\
\hline \multicolumn{4}{|l|}{ Religion } \\
\hline Hindu & $226(80.1)$ & $305(88.7)$ & $531(84.8)$ \\
\hline Muslim & $05(1.8)$ & $10(2.9)$ & $15(2.4)$ \\
\hline Sikh & $20(7.1)$ & $10(2.9)$ & $30(4.8)$ \\
\hline Christian & $27(9.6)$ & $16(4.7)$ & $43(6.9)$ \\
\hline Others & $04(1.4)$ & $03(0.9)$ & $07(1.1)$ \\
\hline \multicolumn{3}{|c|}{ Family Composition } & \\
\hline Nuclear & $185(65.6)$ & $249(72.4)$ & $434(69.3)$ \\
\hline Joint & $97(34.4)$ & $95(27.6)$ & $192(30.7)$ \\
\hline \multicolumn{3}{|c|}{ Marital Status } & \\
\hline Single & $131(46.5)$ & $135(39.2)$ & $266(42.5)$ \\
\hline Married & $151(53.5)$ & $209(60.8)$ & $360(57.5)$ \\
\hline \multicolumn{3}{|c|}{ Whether had dependent children } & \\
\hline$\leq 2$ years & $22(7.8)$ & $35(10.2)$ & $57(9.1)$ \\
\hline
\end{tabular}




\begin{tabular}{|c|c|c|c|}
\hline $2-5$ years & $45(16.0)$ & $49(14.2)$ & $94(15.0)$ \\
\hline$>5$ years & $50(17.7)$ & $73(21.2)$ & $123(19.6)$ \\
\hline No child & $164(58.6)$ & $187(54.4)$ & $352(56.3)$ \\
\hline \multicolumn{4}{|c|}{ Whether had dependent elders in the family } \\
\hline Yes & $130(46.1)$ & $105(30.5)$ & $235(37.5)$ \\
\hline No & $152(53.9)$ & $239(69.5)$ & $391(62.5)$ \\
\hline \multicolumn{4}{|c|}{ Work place Setting } \\
\hline Government & $118(41.8)$ & $286(83.1)$ & $404(64.5)$ \\
\hline Private & $164(58.2)$ & $58(16.9)$ & $222(35.5)$ \\
\hline \multicolumn{4}{|c|}{ Physical co-morbidity } \\
\hline Yes & $42(14.9)$ & $55(16.0)$ & $97(15.5)$ \\
\hline No & $240(85.1)$ & $289(84.0)$ & $529(84.5)$ \\
\hline Substance abuse & $35(12.5)$ & $37(10.7)$ & $72(11.5)$ \\
\hline Yes & $247(87.6)$ & $307(89.2)$ & $554(88.5)$ \\
\hline No & $08(2.8)$ & $94(27.3)$ & $102(16.3)$ \\
\hline Direct dealing with COVID patients (confirmed cases) & $524(83.7)$ \\
\hline Yes & $274(97.2)$ & $250(72.7)$ & \\
\hline No &
\end{tabular}

Four $(0.8 \%)$ HCPs and family members of four HCPs working in COVID health care facilities had tested positive for COVID-19. Out of 167 married female HCPs, 11 were pregnant (6 from COVID and 5 from Non-COVID Health care facilities).

Significantly higher number of heath care professionals working in COVID institutes worked away from their hometown $(p<0.001)$ and had to send their children to relatives /family member's house $(p=0.004)$. However, there was no significant difference with regard to duration of separation from their family $(p=0.384)$ and adverse effect on relationship with partner $(p=0.306)$ (Table 2$)$.

Table 2: Comparison of social impact of COVID-19 pandemic on Health Care Professionals of COVID and NON- COVID health care facilities

\begin{tabular}{|c|c|c|c|c|}
\hline Characteristics & Non-COVID HCPs & COVID HCPs & Total & $\begin{array}{c}\text { Chi square value; } \\
\text { p value }\end{array}$ \\
\hline \multicolumn{5}{|c|}{ Had to send their children to relatives / family member's house $(n=320) *$} \\
\hline Yes & $13(9.2)$ & $37(20.8)$ & $50(15.6)$ & \multirow{2}{*}{$\begin{array}{c}\chi 28.1058 \\
p=0.004\end{array}$} \\
\hline No & $129(90.8)$ & $141(79.2)$ & $270(84.4)$ & \\
\hline \multicolumn{5}{|c|}{ Had to call some family members to stay with their kids $(n=320)$ * } \\
\hline Yes & $28(19.2)$ & $31(17.8)$ & $59(18.4)$ & \multirow{2}{*}{$\begin{array}{l}\chi 20.098 \\
p=0.754\end{array}$} \\
\hline No & $118(80.8)$ & $143(82.2)$ & $261(81.6)$ & \\
\hline \multicolumn{5}{|c|}{ Place of duty $(n=626)$} \\
\hline Away from home town & $90(31.9)$ & $203(59.0)$ & $293(46.8)$ & \multirow{2}{*}{$\begin{array}{c}\chi 245.699 \\
p<0.001\end{array}$} \\
\hline In home town & $192(68.1)$ & $141(41.0)$ & $333(53.2)$ & \\
\hline \multicolumn{5}{|c|}{ Duration of separation from family (in days) (Mean \pm S.D) } \\
\hline Mean \pm S.D & $46.17(98.65)$ & $56.61(86.20)$ & $49.71(92.0)$ & $\mathrm{t}=0.871, \mathrm{p}=0.384$ \\
\hline \multicolumn{5}{|c|}{ Adverse effect on relationship with partner $(n=571)$} \\
\hline Mean \pm S.D & $0.64 \pm 61$ & $0.69 \pm 60$ & $0.66 \pm 60$ & $\mathrm{t}=1.025 ; \mathrm{p}=0.306$ \\
\hline
\end{tabular}


The mean scores of perceived psychological distress among HCPs working in COVID health care facilities were significantly more than their counterparts in Non -COVID health care facilities $(p=0.001)$. There was no significant difference with regard to taking psychotropic medications $(p=0.503)$ and the need to consult a mental health professional $(p=0.466$ ) between HCPs of COVID and Non-COVID institutes (Table 3).

Table 3: Psychological distress among HCPs working in COVID versus NON -COVID health care facilities $(n=626)$

\begin{tabular}{|c|c|c|c|c|}
\hline Characteristics & $\begin{array}{c}\text { Non-COVID Institute } \\
\mathbf{n = 3 4 4}\end{array}$ & $\begin{array}{c}\text { COVID Institute } \\
\mathbf{n = 2 8 2}\end{array}$ & $\begin{array}{c}\text { Total } \\
\mathbf{n = 6 2 6}\end{array}$ & $\begin{array}{c}\text { Test value; } \\
\text { value }\end{array}$ \\
\hline \multicolumn{5}{|c|}{ Perceived psychological distress } \\
\hline Mean \pm S.D & $0.86 \pm 0.41$ & $0.97 \pm 0.39$ & $0.92 \pm 0.40$ & $-3.302 ; 0.001$ \\
\hline \multicolumn{5}{|c|}{ Felt the need to consult a mental health professional } \\
\hline Yes & $28(9.9)$ & $36(10.5)$ & $64(10.2)$ & \multirow{2}{*}{$0.049 ; 0.466$} \\
\hline No & $254(90.1)$ & $308(89.5)$ & $562(89.8)$ & \\
\hline \multicolumn{7}{|c|}{ History of taking psychotropic medication since lockdown due to COVID-19 } \\
\hline Yes & $04(1.4)$ & $06(1.7)$ & $10(1.6)$ & \multirow{2}{*}{$0.105 ; 0.503$} \\
\hline
\end{tabular}

The most important reason for experiencing psychological distress was fear of causing exposure of family members to COVID-19 (52.4\%) followed by uncertainty about when will this pandemic will end (44.25\%) and fear of losing loved ones to COVID-19 (38.34\%) (Table 4).

Table 4: Reasons of psychological distress in HCPs of COVID versus Non COVID institutes*

\begin{tabular}{|c|c|c|c|}
\hline Reasons of Psychological distress & $\begin{array}{c}\text { HCPs (COVID) } \\
(\mathbf{n = 3 4 4 )}\end{array}$ & $\begin{array}{c}\text { HCPs (Non-COVID) } \\
\text { (n=282) }\end{array}$ & $\begin{array}{c}\text { Total } \\
\text { (n=626) }\end{array}$ \\
\hline Fear of falling ill due to COVID-19 & $105(30.52)$ & $74(26.24)$ & $179(28.59)$ \\
\hline Fear of dying due to COVID-19 & $71(20.64)$ & $26(9.22)$ & $97(15.50)$ \\
\hline Fear of causing exposure of family members & $190(55.23)$ & $138(48.94)$ & $328(52.40)$ \\
\hline Fear of losing loved ones to COVID-19 & $131(38.08)$ & $109(38.65)$ & $240(38.34)$ \\
\hline Fear of being put up in quarantine center & $42(12.21)$ & $29(10.28)$ & $71(11.34)$ \\
\hline $\begin{array}{c}\text { Feeling of loneliness, boredom and helplessness } \\
\text { due to being isolated }\end{array}$ & $41(11.92)$ & $32(11.35)$ & $73(11.66)$ \\
\hline $\begin{array}{c}\text { Excessive information overload about COVID- } \\
19 \text { particularly due to influence of social, media }\end{array}$ & $82(23.84)$ & $70(24.82)$ & $152(24.28)$ \\
\hline $\begin{array}{c}\text { Uncertainty about when pandemic will end } \\
\text { Lack of domestic help (maids, baby sitter, cook, } \\
\text { laundrymen etc.) }\end{array}$ & $158(45.93)$ & $119(42.20)$ & $277(44.25)$ \\
\hline $\begin{array}{c}\text { Difficulty balancing family life and professional } \\
\text { life }\end{array}$ & $64(17.44)$ & $28(9.93)$ & $88(14.06)$ \\
\hline $\begin{array}{c}\text { Constant pressure from administrative } \\
\text { authorities }\end{array}$ & $48(13.95)$ & $42(14.89)$ & $106(16.93)$ \\
\hline $\begin{array}{c}\text { Fear of committing unintentional mistakes in } \\
\text { patient management }\end{array}$ & $33(9.59)$ & $31(10.99)$ & $72(11.50)$ \\
\hline Feeling too uncomfortable in PPE & $77(22.38)$ & $33(11.70)$ & $110(17.57)$ \\
\hline Others & $02(0.58)$ & $00(0.0)$ & $2(0.32)$ \\
\hline
\end{tabular}

*Multiple responses, ** Other stressors included not getting good PPE, working without PPE, separation from kids, financial difficulties, not getting salary, family problems, mandatory unwilling extension of residency 
Watching TV/ digital platforms like Netflix, prime videos etc. was the most commonly used coping strategies (55.27\%), followed by spending time on social media (WhatsApp, Facebook etc.) $(51.12 \%)$ and regular exercise (43.93\%) irrespective of the gender and type of health care facility (Table 5). Few (13.4\%) HCPs wanted to quit their job instantly if there were any choice, $15.8 \%$ regretted being a health care professional and $7.7 \%$ were thinking of quitting job after pandemic will be over. There was no significant change in attitude towards medical profession among various groups of HCPs.

Table 5: Gender differences and comparison of coping strategies adopted by HCPs of COVID versus Non COVID health care facilities*

\begin{tabular}{|c|c|c|c|c|c|}
\hline Coping Strategies & $\begin{array}{c}\text { HCPs } \\
(\mathbf{C O V I D )} \\
(\mathbf{n = 3 4 4 )}\end{array}$ & $\begin{array}{c}\text { HCPs } \\
\mathbf{( N o n -} \\
\mathbf{C O V I D}) \\
\mathbf{( n = 2 8 2}\end{array}$ & $\begin{array}{c}\text { Male HCPs } \\
\mathbf{( n = 3 0 0 )}\end{array}$ & $\begin{array}{c}\text { Female } \\
\text { HCPs } \\
\mathbf{( n = 3 2 6 )}\end{array}$ & $\begin{array}{c}\text { Total } \\
\mathbf{( n = 6 2 6 )}\end{array}$ \\
\hline Regular exercise & $132(38.37)$ & $143(50.71)$ & $160(53.33)$ & $115(35.8)$ & $275(43.93)$ \\
\hline Yoga/Meditation & $81(23.55)$ & $83(29.43)$ & $79(26.33)$ & $85(29.07)$ & $164(26.20)$ \\
\hline $\begin{array}{c}\text { Praying and religious } \\
\text { activities }\end{array}$ & $96(27.91)$ & $81(28.72)$ & $59(19.67)$ & $118(36.20)$ & $177(28.27)$ \\
\hline Strengthening hobbies & $73(21.22)$ & $69(24.47)$ & $58(19.33)$ & $84(25.77)$ & $142(22.68)$ \\
\hline Learning new skills & $98(28.49)$ & $97(34.40)$ & $86(28.67)$ & $109(33.44)$ & $195(31.15)$ \\
\hline $\begin{array}{c}\text { Talking to others about } \\
\text { fears and concerns }\end{array}$ & $101(29.36)$ & $53(18.79)$ & $62(20.67)$ & $92(28.22)$ & $154(24.60)$ \\
\hline Engaging with kids/pets & $74(21.51)$ & $78(27.66)$ & $72(24.00)$ & $80(24.54)$ & $152(24.28)$ \\
\hline $\begin{array}{c}\text { Watching TV/ digital } \\
\text { platforms like Netflix, } \\
\text { prime videos etc. }\end{array}$ & $191(55.52)$ & $155(54.96)$ & $164(54.67)$ & $182(55.83)$ & $346(55.27)$ \\
\hline $\begin{array}{c}\text { Spending time on social } \\
\text { media (WhatsApp, } \\
\text { Facebook etc.) }\end{array}$ & $180(52.33)$ & $140(49.65)$ & $155(51.67)$ & $165(50.61)$ & $320(51.12)$ \\
\hline Others** & $14(4.07)$ & $20(7.09)$ & $14(4.67)$ & $20(6.13)$ & $34(5.43)$ \\
\hline
\end{tabular}

*Multiple responses. ** included doing household work, playing games, studying, research work, doing duty.

\section{DISCUSSION}

Our study is among the first few studies to explore the social impact, reasons of psychological distress, coping strategies adopted by healthcare professionals (HCPs) and the change in their attitude towards medical profession during the period of COVID pandemic affecting India. The results of our study show that the healthcare workers working in COVID institutes experienced more psychological distress and significant disruption in routine family life compared to their Non COVID counterparts. These findings are comparable to the earlier studies from China done to assess the mental health of healthcare workers during the COVID19 pandemic where a significant proportion of HCWs (36.9\%) were found to be suffering from sub threshold levels of mental illnesses.(as assessed by PHQ-9, GAD-7, Insomnia Severity Index) ${ }^{\left[{ }^{[9]}\right.}$ In another study from China, a considerably higher proportion of participants i.e. $22.4 \%-50 \%$ of HCWs reported experiencing depression, anxiety, significant distress and insomnia [10].

The index study showed that the most important social impact on HCPs working in COVID institutes was that they were forced to send away their kids to relatives or friends houses. Precautionary safety measure to prevent spread of infection to their kids was the main concern and also possibly because most of them were unable to take care of their young children by themselves as self-isolation measures during the pandemic required them to be quarantined or stay away from their families after duty hours. Also, the HCPs from COVID institutes perceived more psychological distress than their Non- COVID counterparts. The fear of 
spreading coronavirus infection to family members was cited as the most common reason for experiencing psychological distress as reported by about half of the respondents (52.4\%). These findings are in line with study by Cai and others on medical staff in Hunan, where safety of their family from infection was the main concern for medical staff and specially staff between $31-40$ years of age had the greatest concern regarding viral transmission to their families, possibly because most of them had young children further corroborating the findings of our study [11]. This also synchronizes with the findings of study by Vijayraghavan and Singhal on general population of India where $80 \%$ respondents were more worried about the health of their loved ones over their own [12]. Uncertainty about when will this pandemic will end (44.25\%) and fear of losing loved ones to COVID-19 (38.34\%) were the next most important psychological stressors for HCPs.

Healthcare professionals from COVID and Non COVID health care facilities, when, compared for difference in felt need for seeking psychological support from mental health professionals, either in the form of medications or counseling; no significant difference between the two groups was observed. Findings are congruent with the observations from another study from Hunan where medical staff, especially doctors and medical technicians, did not express a significant wish to reduce stress by consulting a psychologist to discuss their emotions [13]. Fear of labeling, stigmatization and discrimination potentially impede healthcare workers to seek counseling and psychotherapeutic interventions [10].

However, one positive finding from the study was that perceived subjective psychological stress was not found to be affecting the relationships of the HCWs with their spouse or other family members significantly. Findings from the study imply that positive relationship with family and spouse might be a significant supportive measure with lesser need for professional help to cope with psychological stress. Results are comparable to findings from another Indian study where majority of the participants reported positive impact of the lockdown on the interpersonal relationship with parents, children, spouse, colleagues, and neighbors [12].

The index study yielded optimistic results when the emotions of the staff regarding recent change in their attitudes towards medical profession during the pandemic were explored. Only $13.4 \%$ of the HCPs wanted to quit their job instantly if given choice, $15.8 \%$ regretted being a health care professional and $7.7 \%$ were thinking of quitting job once the pandemic was over. The personal coping strategies that were most commonly used by HCPs to reduce psychological distress during COVID-19 pandemic were watching TV or digital platforms followed by spending time on social media and regular exercise. Results are in line with the findings from another Indian study on similar subject where about one third to about three fifth of the study participants reported slight or marked increase in activities such as exercise, faith in God, watching movies, internet gaming, playing indoor games, sexual activity, reading books, painting, cooking, and cleaning post lockdown [8]. When it came to the use of coping strategies by HCPs our study had a striking resemblance with the analysis of study by Vijayraghavan and Singhal on general population of India where more than $50 \%$ of the respondents reported high engagement with social media and spending time watching movies/shows online to cope with the stress of COVID-19 lockdown [10].

This study had the limitation of being conducted for a shorter duration and having a cross-sectional study design. Therefore, possible long-term psychiatric sequelae, such as depression and PTSD (Post traumatic stress disorder) could not be not studied. The data from this study was based on subjective responses using questionnaires, and in future studies, these findings should be supported by objective measurements of stress.

\section{CONCLUSIONS}

The study concludes that the COVID-19 pandemic resulted in increased psychological distress for healthcare professionals working in dedicated COVID health care facilities. The main factors associated with perceived distress included social isolation measures requiting healthcare workers to send their kids away, distancing from their families and fear of spreading coronavirus infection to their family members. Importance of positive and social supportive atmosphere and adaptive coping strategies for healthcare professionals for 
prevention of psychological distress and also screening and treating HCPs for psychological distress could not be overemphasized to encourage healthcare workers during these tough times of pandemic.

\section{REFERENCES}

1. Wu Z, McGoogan JM. Characteristics of and important lessons from the coronavirus disease 2019 (COVID19) outbreak in China: summary of a report of 72314 cases from the Chinese centre for disease control and prevention. JAMA 2020;323(13):1239-42

2. World Health Organization, 2020. WHO Director-General's opening remarks at the media briefing on COVID-19-11 March 2020. Retrieved from. https://www.who.int/dg/speeches/detail/who-director-generals-opening-remarks-at-the-media-briefing-on-covid-19---11-march-2020

3. World Health Organization, 2020. WHO coronavirus disease (Covid-19) dashboard. Retrieved from. https://covid19. who.int/?gclid=CjwKCAjwztL2BRATEiwAvnALcs3jNnqz2PXGXZXmFVKjeIiybubcgGOsn6MgIm1s01iEEWVZbGGQRoCkGkQAvD_BwE

4. Ministry of Health and family welfare, 2020. Covid-19 India. Retrieved from https://www.mohfw.gov.in/

5. Lai J, Ma S, Wang Y, Cai Z, Hu J, Wei N, Wu J, et al. Factors associated with mental health outcomes among health care workers exposed to coronavirus disease 2019. JAMA Open 2020;3(3):e203976

6. Li Z, Ge J, Yang M, Feng J, Qiao M, Jiang R, Bi J, et al. Vicarious traumatization in the general public, members, and non-members of medical teams aiding in COVID-19 control. Brain Behav Immun 2020;S08891591(20):30309-3

7. Tan BY, Chew NW, Lee GK, Jing M, Goh Y, Yeo LL, et al. Psychological impact of the COVID-19 pandemic on health care workers in Singapore. Ann Intern Med 2020;M20.

8. Grover S, Sahoo S, Mehra A, Avasthi A, Tripathi A, Subramanyan A, Pattojoshi A, Rao G P, Saha G, Mishra K K, Chakraborty K, Rao NP, Vaishnav M, Singh OP, Dalal P K, Chadda RK, Gupta R, Gautam S, Sarkar S, Sathyanarayana Rao T S, Kumar V, Janardran Reddy Y C. Psychological impact of COVID-19 lockdown: An online survey from India. Indian J Psychiatry 2020;62:354-62

9. Kang L, Li Y, Hu S, Chen M, Yang C, Yang BX, et al. The mental health of medical workers in Wuhan, China dealing with the 2019 novel coronavirus. Lancet Psychiatry 2020; 7:e14.

10. Lai J, Ma S, Wang Y, Cai Z, Hu J, Wei N, et al. Factors associated with mental health outcomes among health care workers exposed to coronavirus disease 2019. JAMA Open 2020;3:e203976

11. Cai H, Tu B, Ma J, Chen L, Fu L, Jiang Y, Zhuang Q. Psychological Impact and Coping Strategies of Frontline Medical Staff in Hunan Between January and March 2020 During the Outbreak of Coronavirus Disease 2019 (COVID 19) in Hubei, China. Med Sci Monit 2020;26:e924171.

12. Vijayaraghavan P, Singhal D. A Descriptive Study of Indian General Public's Psychological responses during COVID-19 Pandemic Lockdown Period in India. Retrieved from https://psyarxiv.com/jeksn/download?format=pdf

13. Zheng W, Cai DB, Xiang YQ, Jiang WL, Sim K, Ungvari GS, Huang X, Huang XX, Ning YP, Xiang YT. Adjunctive intranasal esketamine for major depressive disorder: A systematic review of randomized doubleblind controlled-placebo studies. J Affect Disord 2020;265:63-70.

\footnotetext{
$* * * * * * * * * * * * * * * * * * * * * * * * * * * * * * * * * * * *$

Acknowledgements - Nil

Conflict of Interest - Nil

Funding - Nil
} 